\title{
Using PCR Technician in Prenatal Diagnosis of Fetal Gender
}

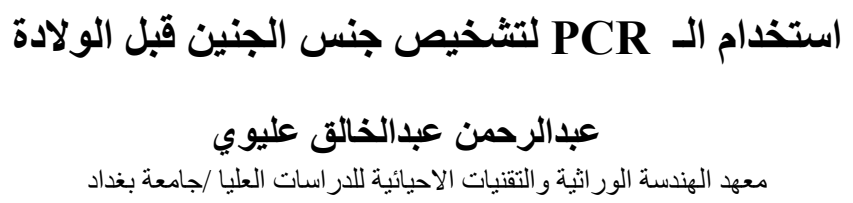

Abdulrahman A. Oleiwi

Institute of Genetic Engineering and Biotechnology for Post Graduate Studies / Baghdad University

\section{理}

Abstract

hole blood samples were obtained from 30 pregnant women at $15-24$ weeks of gestation. DNA was extracted from each plasma or serum sample. To detect the Y-chromosome specific marker DYS14 in the maternal blood, (Polymerase Chain Reaction) PCR were carried out for each DNA extract. The PCR products were analyzed by $1.5 \%$ agarose gel electrophoresis and ethidium bromide staining. The results compared with fetal gender after delivery. The result of delivery revealed that 13 pregnant women had a male fetus and the remaining 17 pregnant women had a female fetus and DYS14 was detected in all plasma and serum samples obtained from pregnant women and revealed that 13 pregnant women had a male fetus and the remaining 17 pregnant women had a female fetus. The PCR sensitivity for detecting the gender of fetus from maternal whole blood at 15-24 weeks of gestation was $100 \%$ in both plasma and serum, DYS14 was not detected in the DNA from any of the 17 pregnant women carrying a female fetus. The results showed that PCR analysis of maternal plasma and serum can be used to diagnose fetal gender.

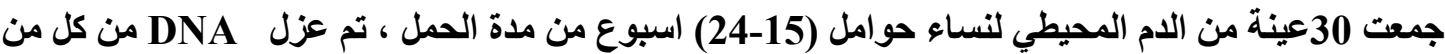

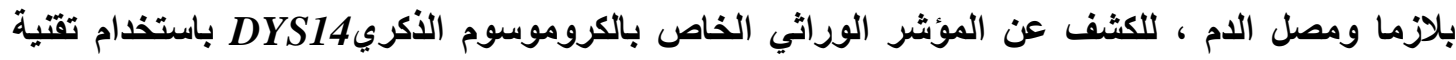

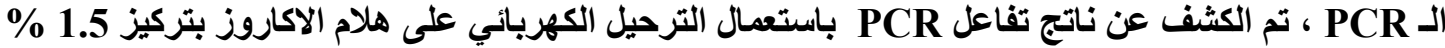

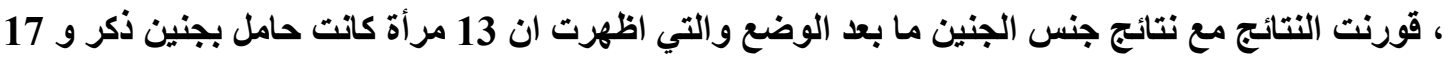

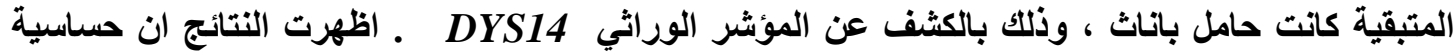
تفاعل الـ PCR في الكثف عن جنس الجنين في النساء الحوامل باستعمال الام المحيطي للحوامل وبعمر حمل

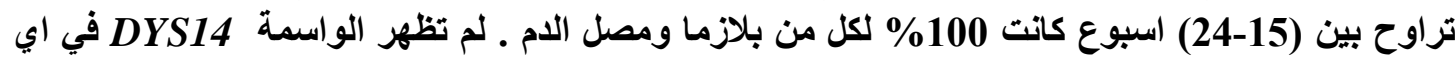
من الـ 17 من النساء الحوامل بإناث ـ اظهرت النتائج امكانية استعمال PCR في الكشف عن عن جنس الجنين ما

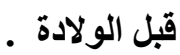

\section{Introduction}

In 1997 a pioneer study showed that: the presence of fetal DNA in maternal plasma and serum, using the detection of $\mathrm{Y}$ - chromosomal DNA sequences derived from a male fetus as a model system. This work produced the first demonstration of fetal DNA in maternal plasma and serum and the realization that maternal plasma and serum DNA is a chemric mixture of fetal and maternal DNA [1,2].

During early pregnancy fetal DNA concentrations were on average, $3.4 \%$ of the total DNA in the maternal plasma and $0.13 \%$ in serum. Even though the highest concentration of fetal DNA seems to be present in maternal plasma [2]. Some

Keywords: Prenatal diagnosis, maternal blood, fetal gender, PCR 
researchers have had better specificity and sensitivity results with maternal serum samples [3], whereas others suggested using the maternal plasma $[1,4,5,6]$. Comparable results with both maternal plasma and serum have been reported when highly sensitive techniques, such as real-time quantitative polymerase chain reaction (PCR), are used for the determination of fetal gender or RhD (Rhesus factor) status [7, 8]. However, expensive equipment renders their application difficult in a routine setting. Thus, especially for diagnostic facilities with limited financial resources, a simple, cost efficient, reliable and replicable conventional PCR technique may be an alternative solution to utilize this analysis in a routine clinical setting.

The aim of this study is to describe the diagnosis of fetal gender using conventional PCR for DNA extracted from the maternal plasma and serum. This method for diagnosing fetal gender can be used for clinical pre-testing to determine whether invasive prenatal diagnoses, such as amniocentesis and chorionic villi sampling, should be performed on a fetus having a risk of X-linked recessive inheritance. In addition the results also indicated that it can accurately detect fetal DNA; thus, fetal DNA in maternal plasma and serum may be considered a new material for noninvasive prenatal diagnosis.

\section{Materials and Methods \\ Sample collection}

Whole blood samples were obtained from 30 pregnant women undergoing amniocentesis at private clinic in Baghdad during the period from (Jan. - June) 2008. Pregnant women participating in this study were selected randomly. At the time of blood collection, the gestational stages ranged from 15 weeks \pm 6 days to 24 weeks \pm 3 days.

Peripheral blood samples obtained from 5 healthy men were used to determine the PCR specificity and sensitivity, whereas peripheral blood samples obtained from 5 non-pregnant women served as negative controls. In each case, $4 \mathrm{~mL}$ of peripheral blood was collected into an EDTA- tube for plasma separation, and $6 \mathrm{~mL}$ of peripheral blood was collected into a collection tube containing no anticoagulant for serum separation. The blood samples were centrifuged at $3000 \mathrm{~g}$; the plasma and serum were carefully removed from their tubes and transferred into plain polypropylene tubes. The plasma and serum samples were centrifuged at $3000 \mathrm{~g}$ twice and plasma and serum samples were transferred into fresh polypropylene tubes. The samples were stored at $-20{ }^{\circ} \mathrm{C}$ until further processing.

\section{DNA extraction}

DNA was extracted from the plasma and serum samples by wizard genomic (DNA purification kit, Promega) according to the "Isolating Genomic DNA from whole blood protocol". DNA extracted from $600 \mu \mathrm{l}$ of plasma and $800 \mu \mathrm{l}$ of serum in each case. The volume of the extracted DNA solution was usually $100 \mu 1$, concentrated to a volume of $20 \mu \mathrm{l}$ by ethanol precipitation. Each DNA solution extracted from the healthy men was serially diluted from 1:10 to $1: 10000$ to estimate the sensitivity of PCR. 


\section{PCR Amplification}

The Y-chromosome-specific marker DYS14 (239bp) was amplified for detection of fetal DNA in maternal plasma and serum. Used the primer sets (5'CTAGACCGCCAGAGGCGCCAT'3) as upstream primer, and (5' TAGTAACCCACGCCTGCTCCGG '3) as downstream primer to amplify DYS14 marker according to [9]. (Primers set supplied by Alpha DNA Company,USA).

The PCR amplification was performed in a total volume of $25 \mu 1$ containing $5 \mu 1$ DNA, $12.5 \mu \mathrm{l}$ Go Taq green master mix $2 \mathrm{X}$ (green master mix is a premixed ready to use solution containing Taq DNA polymerase, dNTPs, $\mathrm{MgCl}_{2}$ and reaction buffers at optimal concentrations for efficient amplification of DNA template by PCR supplied by promega (Promega corporation 2008, USA). $1 \mu 1$ of each primer $(50 \mathrm{pmol} / 1 \mu \mathrm{L})$ and up to $25 \mu 1$ with nucleases free water.

The thermal cycling was as follows: Denaturation at $94{ }^{\circ} \mathrm{C}$ for $5 \mathrm{~min}$, followed by 40 cycles of $94{ }^{\circ} \mathrm{C}$ for $30 \mathrm{~s}, 62^{\circ} \mathrm{C}$ for $1 \mathrm{~min}$, and $72{ }^{\circ} \mathrm{C}$ for $2 \mathrm{~min}$, with final incubation at $72{ }^{\circ} \mathrm{C}$ for $7 \mathrm{~min}$. The PCR products were separated by $1.5 \%$ agarose gel electrophoresis and visualized by exposure to ultraviolet light $302 \mathrm{~nm}$ after ethidium bromide staining.

The PCR results were compared with the fetal gender after delivery. Each DNA solution extracted from the plasma and serum of pregnant women, healthy men, and no pregnant women was tested two times in different PCR sessions. Another PCR run were performed for positive result for confirmation.

\section{Results and Discussion}

DYS14 gender marker was detected in both plasma and serum samples from 30 pregnant women. PCR result revealed that 17 of the pregnant women were carrying a female fetus and the remaining 13 pregnant women were carrying a male fetus. Figure

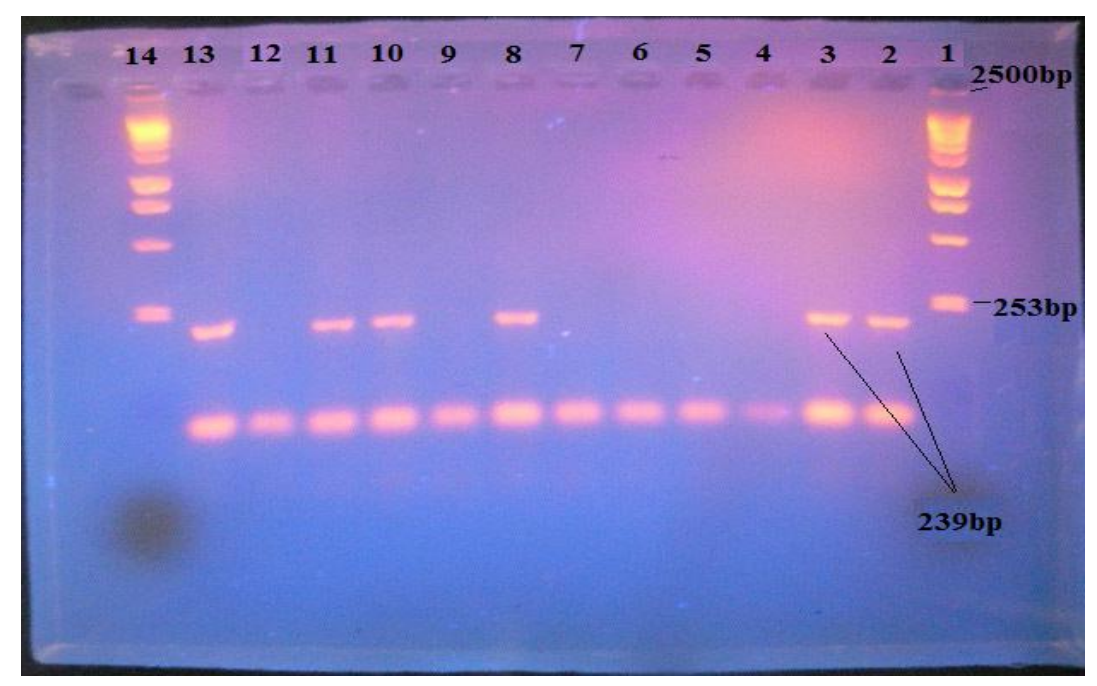

Fig (1): Agarose gel electrophoresis $(1.5 \%, 5 \mathrm{v} / \mathrm{cm})$ for detection of DYS14 sequences in maternal plasma by PCR. Lanes 1and 14, 1kb DNA size ladder, Lanes 8, 10, 11, and 13: DNA solutions from the plasma of male-bearing pregnant women amplified for the DYS14marker, Lanes 9, 12:

DNA solutions from the plasma of female-bearing pregnant women amplified for the DYS14sequence, Lanes 4 and 5: Female (-ve control), Lanes 6 and 7, distilled water without DNA that underwent PCR for DYS14. 


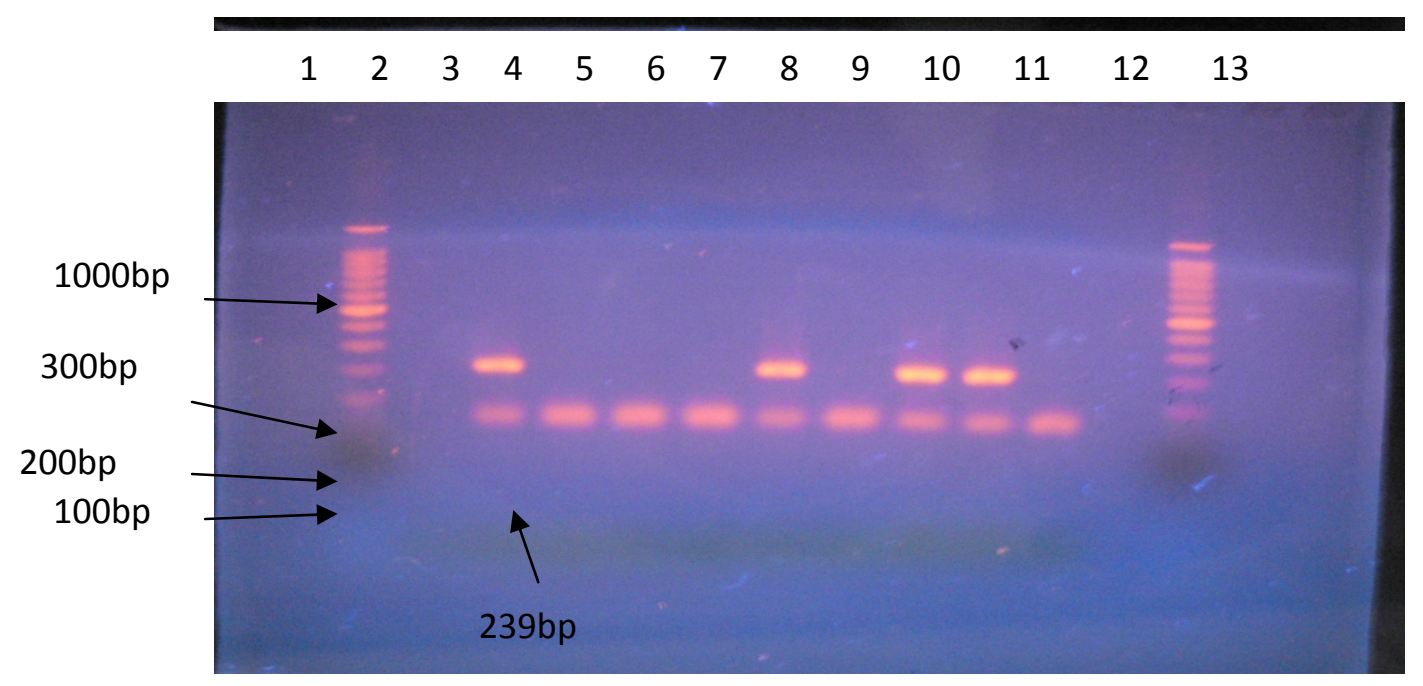

Fig (2): Agarose gel electrophoresis $(1.5 \%, 5 \mathrm{v} / \mathrm{cm})$ for detection of DYS14 sequences in maternal serum by PCR. Lanes 1and 13, 100pb DNA size ladder, Lanes 2, 12: distilled water without DNA that underwent PCR for DYS14. Lane 3: DNA solutions from the serum of healthy males (+ve control). Lane 4: DNA solutions from the serum of healthy no pregnant females (-ve control). Lanes 5, 6, 8 and 11 female-bearing pregnant women amplified for the DYS14sequence, Lanes 7, 9 and 10: DNA solutions from the serum of male-bearing pregnant women amplified for the DYS14marker.

In dilutions series prepared with DNA extracted from plasma and serum of all five healthy men, the detection limits were 1:100 and 1:1000 respectively for DYS14 marker dilutions, figure (3).
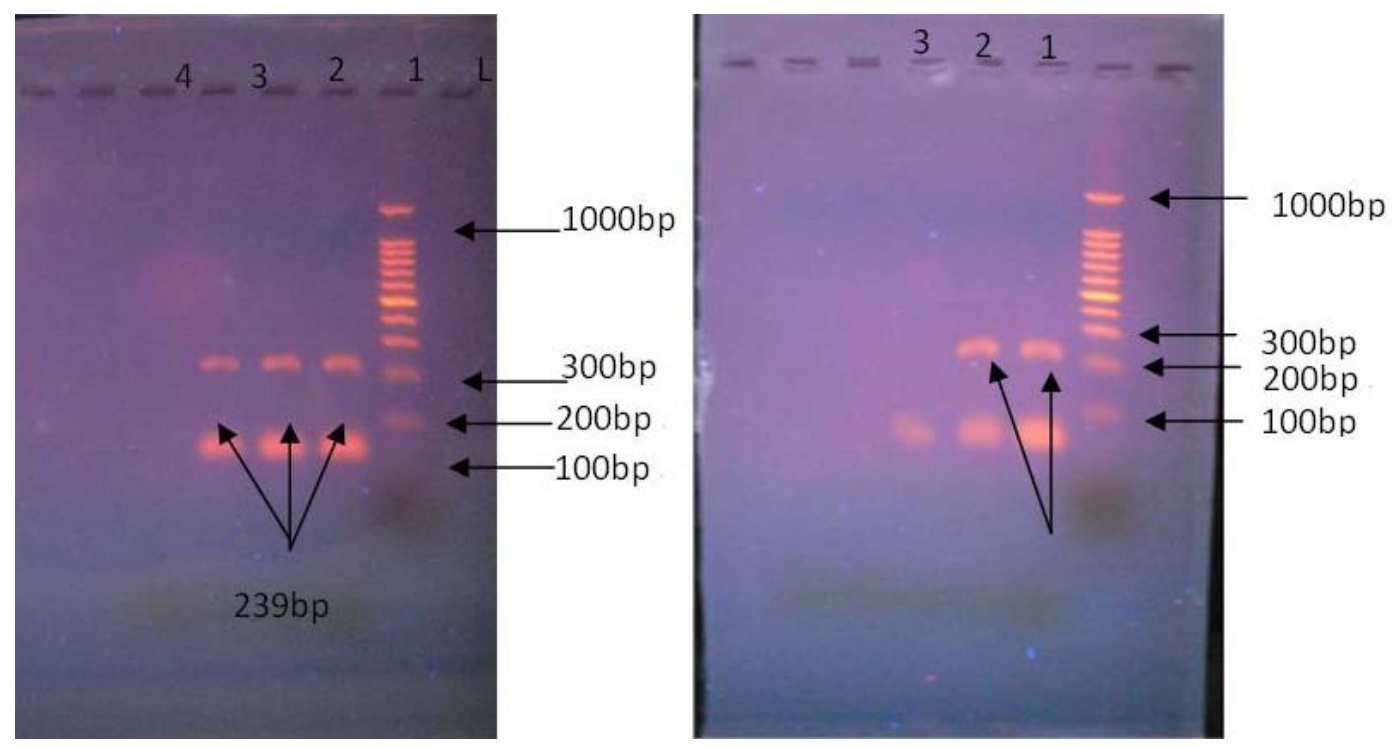

Fig 3:

A: Agarose gel electrophoresis (1.5\%, $5 v / \mathbf{c m})$ for PCR sensitivity: Serial dilutions of DNA extracted from male serum were amplified for DYS14. Lane 1: Dilution: 1:10, Lane 2: Dilution 1:100, Lane 3: Dilution 1:1000, Lane 4: Dilution1:10000, Lane L: Ladder 100bp

B: Agarose gel electrophoresis $(1.5 \%$, $5 \mathrm{v} / \mathrm{cm})$ for PCR sensitivity: Serial dilutions of DNA extracted from male plasma were amplified for DYS14. Lane 1: Dilution: 1:10, Lane 2: Dilution 1:100, Lane 3: Dilution 1:1000, Lane L: Ladder 100bp 
DYS14 was not detected in the DNA extracted from any of the five non pregnant women. The sensitivity of the conventional PCR for detecting male-bearing pregnancies from maternal whole blood at 15-24 weeks of gestation was $100 \%$ in both plasma and serum. Whereas the sensitivity of fluorescence in situ hybridization or PCR using enriched fetal NRBCs (Nucleated Red Blood Cells) ranged from (55, 86) $\%[10,11]$

However, these methods are time-consuming, labor-intensive and their sensitivities are quite low for a clinical application. On the other hand, when used maternal plasma and serum in this study, the method had the highest sensitivity $100 \%$, comparable to the previously mentioned methods. The method is based on the presence of fetal DNA in maternal plasma and serum, a finding that was reported for the first time by [1]. The high sensitivity for detecting fetal DNA with conventional PCR is attributable to a high concentration of fetal DNA in maternal plasma and serum $[12,13]$.

The detection of DYS14 sequences in the DNA extracted from the serum of malebearing pregnant women indicates that the fractional concentration of fetal DNA in maternal serum is $>0.1 \%$, based on the assumption that the total DNA present in male serum is equal to that in maternal serum [14].

Using real-time quantitative PCR (TaqMan PCR) showed that the fractional concentration of fetal DNA in maternal serum in early pregnancy (11-17) weeks of gestation is $(0.014-0.54) \%$ (mean, $0.13 \%$ ). This concentration is similar to that in enriched fetal NRBCs $(0.001-5) \%$ in all cellular fractions after fluorescenceactivated cell sorting [15].

The results agreed a little with resent of [1] who found no significant difference in accuracy for diagnosing fetal gender between their maternal plasma-based method and their maternal serum-based method (the sensitivity of their plasma-based method for male-bearing pregnancies was $80 \%$, and that of their serum-based method was $70 \%$ ) and differ from [5] results which found that the accuracy of their method for fetal gender diagnosis was significantly higher when they used maternal plasma rather than maternal serum (the sensitivity of their plasma-based method for diagnosing male-bearing pregnancies was $89 \%$, and that of their serum-based method was $46 \%$ ), it is obvious that the PCR protocol of this method was not essentially different from the methods of [1,5] so the difference could be as a result of differences in the methods used for DNA extraction. In this study DNA extraction method was performed using Promega wizard genomic (DNA purification kit) the whole blood protocol reagent set, whereas [1,5] used methods based on heat extraction. Also may be the use of a ready-to-use PCR master mixture significantly reduced the risk of nonspecific and/or false positive amplifications and eliminated insufficient PCR amplification due to primer dimerization formed at low temperatures during PCR setup or the initial PCR cycle.

The detection of viral DNA in human plasma or serum is similar to that of fetal DNA in maternal plasma or serum in regard to "foreign DNA" in host plasma or serum. Viral DNA in serum could be detected with higher sensitivity than could viral DNA in plasma (16). The sensitivity for detecting viral DNA was similar for serum and plasma (17). 
There are other Y-chromosome-specific sequences, including DYZ1, sex-determining region $\mathrm{Y}(S R Y)$, zinc finger protein, Y-encoded (ZFY), and the amelogenin-like gene on Y chromosome (AMELY). DYS14 sequence was used frequently for diagnosis of fetal gender because it is superior for this purpose. The detection limit of DYS14 sequence was high in PCR conditions; therefore, the sensitivity of DYS14 for the detection of male fetal DNA is potentially higher [18]. However, in the present study, the sensitivity of the DYS14 sequence for the detection of fetal male DNA was the same in both maternal plasma and serum at 15-24 weeks of gestation. These results were depended on the concentration of male fetal DNA, and the concentration of male fetal DNA is known to increase with gestational age [2].

The detection limits of PCR in serial dilutions for the DYS14 between plasma and serum was differ, this result may be indicates a lower efficiency of DNA extraction from plasma than from serum. This lower extraction efficiency might be attributable to cryoprecipitates in the plasma [18]. And the DNA extraction method may play main role in the success of gender diagnosis.

Due to the successful of used maternal plasma and serum for diagnosis of fetal gender, the diagnostic method used in this study may be useful in place of invasive prenatal diagnostic methods such as amniocentesis and chorionic villi sampling in cases of X-linked recessive inheritance. If a fetus has a risk of X-linked recessive inheritance and is found to be female by the maternal plasma and serum-based method, use of an invasive prenatal diagnostic method may not be necessary. The method could be used for detection of inherited autosomal-dominant diseases, of diseases caused by germline mutations, and fetal RhD status [19]

In Iraq the near future, maternal plasma and serum may play an important and powerful role in noninvasive prenatal diagnosis, especially the method could estimate the cases as early as 5 th -10 th weeks of gestation $[1,6,20]$.

\section{References}

1. Lo, YMD.; Corbetta, N.; Chamberlain, PF.; Rai, V.; Sargent, IL.; Redman, CW. (1997). Presence of fetal DNA in maternal plasma and serum, Lancet. 350:485487.

2. Lo, YMD.; Tein, MS.; Lau, TK.; Haines, CJ.; Leung, TN.; Poon, PM. ( 1998). Quantitative analysis of fetal DNA in maternal plasma and serum: implications for noninvasive prenatal diagnosis, Am J Hum Genet. 62:768-775.

3. Huang, Y.; Chen, X.; Kong, S. (2002). Detect maternal serum fetal DNA for prenatal diagnosis, Zhonghua Fu Chan Ke Za Zhi. 37: 715-717.

4. Tachdjian, G.; Costa , J.M.; Frydman, N. (2002). Contribution of genotyping for fetal sex determination in maternal serum in preimplantation genetic diagnosis for X-linked diseases, Gynecol Obstet Fertil. 31: 1030-1035.

5. Houfflin-Debarge, V.; OÕDonnell, H.; Overton, T. (2000). High sensitivity of fetal DNA in plasma compared to serum and nucleated cells using unnested PCR in maternal blood, Fetal Diagn Ther. 15: 102- 107.

6. Tungwiwat, W.; Fucharoen, G.; Ratanasiri, T. (2003). Non-invasive fetal sex determination using a conventional nested PCR analysis of fetal DNA in maternal plasma, Clin Chim Acta. 334: 173-177. 
7. Costa, J.M.; Benachi, A.; Gautier, E. (2001).First trimester fetal sex determination in maternal serum using real-time PCR, Gynecol Obstet Fertil. 30: 953-957.

8. Hromadnikova, I.; Houbova, B.; Hridelova, D. (2003). Replicate real time PCR testing of DNA in maternal plasma increases the sensitivity of non invasive fetal sex determination, Prenat Diagn. 23: 235-238.

9. Soo-Kyung, C.; Jin-Woo, K.; So-Yeon, P.; Young-Mi, K.; Jin-Mee, K.; HyunMee, R.; Jae-Sub, Y.; Song-Ro, Y. (1999). Retroactive DNA analysis for sex determination and dystrophin gene by polymerase chain reaction with archived cytogenetic slides, Exper Mol Med. 31(1): 36-41.

10. Valerio, D.; Aiello, R.; Altieri, V. (1997). Isolation of fetal erythroid cells from maternal blood based on expression of erythropoietin receptors, Mol Hum Reprod.3:451-455

11. Sohda, S.; Arinami, T.; Hamada, H.; Nakauchi, H.; Hamaguchi, H.; Kubo, T. ;( 1997) .The proportion of fetal nucleated red blood cells in maternal blood: estimation by FACS analysis, Prena. Diagn.17:743-752

12. Lo, YMD.; Patel, P. ; Baigent, C.N.; Gillmer, M.; Chamberlain, P.; Sampietro, M. ( 1993). Prenatal sex determination from maternal peripheral blood using the polymerase chain reaction, Hum. Genet.90:483-488

13. Thomas, M.R.; Tutschek, B.; Frost, A.; Rodeck, C.H.; Yazdani, N.; Craft, I. (1995).The time of appearance and disappearance of fetal DNA from the maternal circulation, Prenat. Diagn.15:641-646

14. Hamada, H.; Arinami, T.; Kubo, T.; Hamaguchi, H.; Iwasaki, H. (1993). Fetal nucleated cells in maternal peripheral blood: frequency and relationship to gestational age, Hum. Genet.91:427-432.

15. Bianchi, D.W.; Shuber, A.P.; DeMaria, M.A.; Fougner, A.C.; Klinger, K.W. (2000). Fetal cells in maternal blood: determination of purity and yield by quantitative polymerase chain reaction, Am. J. Obstet. Gynecol. 171:22-26.

16. Hamprecht, K.; Mikeler, E.; Jahn, G. (1997). Semi-quantitative detection of cytomegalovirus DNA from native serum and plasma by nested PCR: influence of DNA extraction procedures, J. Virol. Methods. 69:125-135.

17. Boom, R.; Sol, C.J.; Schuurman, T.; Breda, A.; Weel, J.F.; Beld, M.; Berge, I.J.; and Jong, M.(2002).Human Cytomegalovirus DNA in Plasma and Serum Specimens of Renal Transplant Recipients Is Highly Fragmented, J.Clini.Microbio. 40(11):4105-4113.

18. Honda, H.; Miharu,N.; Ohashi,Y.; and Ohama,K.(2001).Successful diagnosis of fetal gender using conventional PCR analysis of maternal serum. Clini Chem. 47:141-146.

19. Lo, YMD.; Hjelm, N.M.; Fidler, C.; Sargent, I.L.; Murphy, M.F.; Chamberlain, P.F. (1998). Prenatal diagnosis of fetal $\mathrm{RhD}$ status by molecular analysis of maternal plasma, Engl J Med.339:1734-1738.

20. Birch, L.; English, C.A.; O’Donoghue, K.; Barigye, O.; Fisk, N.M. and Keer, J. (2005). Accurate and Robust Quantification of Circulating Fetal and Total DNA in Maternal Plasma from 5 to 41 Weeks of Gestation. J.Clin. Chemi. 51:312-320. 